Jurnal Pendidikan Dasar, 6 (1) Juni 2018

\title{
PENGARUH MODEL PEMBELAJARAN BAMBOO DANCING TERHADAP HASIL BELAJAR PADA MATA PELAJARAN IPA SISWA KELAS VI SDN 11 NANGA PINOH
}

\author{
Lia Kastia ${ }^{1}$, Rachmat Sahputra ${ }^{2}$, Eko Fery Haryadi Saputra ${ }^{3}$ \\ ${ }^{1}$ Mahasiswa Lulusan Program Studi PGSD Tahun 2018 \\ ${ }^{2}$ Dosen FKIP Universitas Tanjungpura Pontianak \\ ${ }^{3}$ Dosen STKIP Melawi
}

Jl. RSUD Melawi km. 04 Kec. Nanga Pinoh Kab. Melawi Kalimantan Barat

J1. Prof. Dr. H. Hadari Nawawi, Bansir Laut, Kota Pontianak, Kalimantan Barat

Kastialia@gmail.com,rahmat_ui@yahoo.com, ferryryadi@gmail.com

\begin{abstract}
This study aims to see the significance effect of bamboo dancing learning model on learning outcomes in natural science subjects (IPA). The location of this research is at State Elementary School No. 11 Nanga Pinoh. The location of this research is at State Elementary School No. 11 Nanga Pinoh. This type of research is a pre-experiment research with one-group pretest-posttest design. The population of this research is the students of class VI SDN 11 Nanga Pinoh academic year 2017/2018. The sample was obtained by class VI with 29 students. The data analysis technique used is t-test. The result of this research shows that the influence of bamboo dancing learning model on the result of study on the subject of Natural Science (IPA) obtained by $\mathrm{t}$-test calculation is obtained tcount $=3,75>$ table $=2,10$. based on the results of data analysis obtained conclusion from pretest value before applied bamboo dancing learning model that is with average 60,46 and posttest value after applied bamboo dancing learning model that is with average 77,47. meaning the results of this study indicate that the influence of bamboo dancing learning model has a significant effect on the results of learning, especially on subjects of Natural Sciences (IPA). Based on the data analysis of N-Gain High category score of 6 students, medium category as many as 16 students, and low category as many as 7 students.
\end{abstract}

Keywords: Bamboo Dancing Learning Model, Science learning out comesn Nature (Science Learning)

Abstrak: Penelitian ini bertujuan Mengetahui hasil belajar siswa pada mata
pelajaran IPA di kelas VI SDN 11 Nanga Pinoh sebelum dan sesudah
menggunakan model pembelajaran Bamboo Dancing. Tempat pelaksanaan
penelitian ini adalah di Sekolah Dasar Negeri No. 11 Nanga Pinoh. Jenis
penelitian ini adalah penelitian pre-eksperimen dengan design one-group
pretest-posttest. Populasi penelitian ini adalah siswa kelas VI SDN 11 Nanga
Pinoh tahun ajaran 2017/2018. Sampel diperoleh kelas VI dengan jumlah 29
siswa. Teknik analisis data yang digunakan adalah menggunakan uji-t. Hasil
penelitian menunjukkan pengaruh signifikan pengaruh model pembelajaran
bamboo dancing terhadap hasil belajar pada mata pelajaran Ilmu Pengetahuan
Alam (IPA) yang diperoleh hasil perhitungan uji-t diperoleh thitung $=3,75>$
$t_{\text {tabel }}=2,10$. berdasarkan hasil analisis data diperoleh kesimpulan dari nilai
pretest sebelum diterapkan model pembelajaran bamboo dancing yaitu dengan
rata-rata 60,46 dan nilai posttest sesudah diterapkan model pembelajaran
bamboo dancing yaitu dengan rata-rata 77,47 . artinya hasil penelitian ini 17| J P D, p - I S S N : $2252-8156$, e - I S S N : $2579-3993$ 
menunjukkan bahwa pengaruh model pembelajaran bamboo dancing ini berpengaruh signifikan terhadap hasil belajar khususnya pada mata pelajaran Ilmu Pengetahuan Alam (IPA). Berdasarkan analisis data hasil nilai N-Gain kategori Tinggi sebanyak 6 siswa, kategori sedang sebanyak 16 siswa, dan kategori rendah sebanyak 7 siswa.

Kata Kunci: Model Pembelajaran Bamboo Dancing, hasil belajar Ilmu Pengetahuan Alam (IPA).

$\mathrm{P}$ endidikan di sekolah merupakan suatu proses yang dilaksanakan secara formal maupun informal. Dalam proses pembelajaran diperlukan guru sebagai pendidik dan siswa sebagai peserta didik. Salah satu tugas guru adalah mengajar. Sebagai pengajar guru tidak hanya memberikan dan menyampaikan informasi tentang ilmu pengetahuan. Menurut purwanto (2014: 18) pendidikan merupakan sebuah proses kegiatan yang disengaja atas input siswa untuk menimbulkan suatu hasil yang diinginkan sesuai tujuan yang ditetapkan.

IPA adalah salah satu mata pelajaran yang dipelajari oleh siswa di sekolah dasar. Pada proses pembelajaran IPA peneliti menemukan permasalahan-permasalahan yang terjadi. Permasalahan yang dimaksud biasanya berupa kesulitan-kesulitan siswa dalam menerima maupun mengolah hasil pembelajaran yang diberikan oleh guru. Seperti halnya pada saat peneliti melakukan observasi dan wawancara pada tanggal 21 maret 2017 dengan guru kelas VI di SDN 11 Nanga Pinoh Kabupaten Melawi, peneliti menemukan beberapa permasalahan yang terjadi saat berlangsungnya proses pembelajaran, yaitu kurangnya pemahaman siswa terhadap materi IPA yang diajarkan, siswa tidak ada yang bertanya atau pun komentar memberikan pendapat materi yang disampaikan oleh guru, model pembelajaran yang digunakan guru belum bervariasi, rendahnya tingkat ketuntasan nilai siswa dari jumlah 29 siswa hanya $31 \%$ siswa yang nilainya sudah mencapai KKM (Kriteria Ketuntasan Minimal).

Berdasarkan permasalahan tersebut, maka besar kemungkinan proses pembelajaran tidak dapat berlangsung dengan baik karena penggunaan model yang digunakan guru dalam menyampaikan materi sangat berpengaruh terhadap hasil belajar siswa. Untuk memperbaiki hal tersebut peneliti ingin mencoba menggunakan model pembelajaran bamboo dancing. Bahwa model pembelajaran bamboo dancing adalah model pembelajaran yang bertujuan agar siswa saling berbagi informasi bersama- sama dengan pasangan yang berbeda dalam waktu singkat secara teratur yang mencangkup untuk pencapaian hasil belajar siswa pada mata pelajaran IPA. Purwanto (dalam Sari, 2011) mengatakan hasil belajar adalah perubahan perilaku 
peserta didik akibat belajar. perubahan perilaku disebabkan karena dia mencapai penguasaan atas sejumlah bahan yang diberikan dalam kegiatan belajar mengajar yang sedang dilakukan. Perubahan perilaku disebabkan karena dia mencapai penguasaan atas sejumlah bahan yang diberikan dalam proses belajar mengajar.

Benjamin S. Bloom dalam Praja (2010) mengkategorikan hasil belajar ke dalam tiga aspek, yaitu aspek kognitif, aspek afektif dan aspek psikomotorik. Ketiga tingkatan itu dikenal dengan istilah "Bloom Taxonomy" (Taksonomi Bloom). Aspek Kognitif meliputi kemampuan pengembangan intelektual (Knowledge) dengan tingkatan, yaitu: 1) Hapalan, 2) Pemahaman, 3) Penerapan, 4) Analisis, 5) Sintesis, 6) Evaluasi. Aspek afektif berkenaan dengan sikap nilai. Carlroger (dalam Masrurah, 2010) menyatakan bahwa sikap seseorang dapar diramalkan perubahannya, bila seseorang telah memiliki penguasaan tingkat kognitif yang tinggi, aspek afektif juga berkenaan dengan perkembangan emosional individual, selain dari sikap apresiasi, dan motivasi.

Bloom (dalam masrurah, 2010 membagi aspek efektif dalam lima kategori, yaitu: 1) Penerimaan, 2) Jawaban, 3) Penilaian, 4) Pengorganisasian, 5) Karakteristik. Aspek Psikomotorik hasil psikomotorik tampak dalam bentuk keterampilan (skill) dan kemampuan- kemampuan bertindak individu. Aspek psikomotorik dikemukakan oleh Dave (dalam Masrurah 2010) dibagi menjadi lima kategori, yaitu: 1) Penipuan, 2) Manipulasi, 3) Ketepatan, 4) Artikulasi, 5) Pengalamiahan. Tetapi, peneliti menggunakan satu aspek saja yaitu aspek kognitif. Strategi ini cocok untuk materi yang membutuhkan pengalaman, pikiran dan informasi antar siswa. Meskipun bernama bamboo dancing, tidak menggunakan bambu. Siswa yang berjajarkan yang diibaratkan sebagai bambu. Beranjak dari pemaparan permasalahan tersebut, maka diterapkan model bamboo dancing ini diharapkan pemahaman siswa tentang suatu tentang suatu konsep akan meningkat sehingga dapat meningkatkan hasil belajar.

Shoimin (2016: 31) model pembelajaran bamboo dancing bertujuan agar siswa saling berbagi informasi bersama- sama dengan pasangan yang berbeda dalam waktu singkat secara teratur. Strategi ini cocok untuk materi yang membutuhkan pengalaman, pikiran dan informasi antar siswa. Huda (2014: 250) bamboo dancing ini adalah keunggulan strategi adanya struktur yang jelas dan memungkinkan siswa untuk saling berbagi informasi dengan singkat dan teratur serta memberi kesempatan pada siswa untuk mengolah informasi dan meningkatkan keterampilan komunikasi. 


\section{METODE PENELITIAN}

Bentuk penelitian yang digunakan pada penelitian ini adalah penelitian eksperimen. Penelitian ini bersifat kualitatif yaitu data- data yang diperoleh dianalisis dengan rumus-rumus statistik untuk memperoleh kesimpulan. Menurut Djam'an Satori (2013: 22) penelitian kualitatif adalah penelitian yang menekankan pada quality atau hal yang terpenting dari sifat suatu barang/ jasa. Jenis penelitian yang digunakan pada penelitian ini adalah preeksperimen design yang menggunkan jenis design penelitian one-group-pretest-posttest design (Sugiyono, 2015:74).

Hal pertama dalam pelaksanaan eksperimen menggunakan design ini dilakukan dengan memberikan pretest $\left(\mathrm{O}_{1}\right)$ dan kemudian diukur hasil belajar siswa menggunakan lembar tes (soal) untuk mengukur hasil belajar siswa, setelah mendapatkan data tentang hasil belajar siswa, maka selanjutnya dilakukan treatment (X) dengan model pembelajaran bamboo dancing. Setelah adanya perlakuan kepada siswa, maka dapat diukur lagi hasil belajar siswa menggunakan lembar tes (soal) posttest $\left(\mathrm{O}_{2}\right)$, instrument ini untuk mengukur hasil belajar IPA siawa dari eksperimen dimana hasil belajar siswa ada perubahan tidak sama sekali. Adapun instrumen yang digunakan untuk pretest dan posttest dalam penelitian yang dilaksanakan ini adalah dengan menggunakan lembar tes (soal) hasil belajar IPA siswa.

Populasi pada penelitian ini adalah seluruh subjek atau seluruh data siswa kelas VI SDN 11 Nanga Pinoh. Sampel yang dipilih peneliti adalah dengan menggunakan teknik purposive sampling artinya sampel pada penelitian ini adalah satu kelas VI SDN 11 Nanga Pinoh yang terdiri dari 29 siswa dengan rincian 15 orang siswa laki- laki dan 14 orang siswa perempuan. Variabel bebas dalam penelitian ini adalah model pembelajaran bamboo dancing. Variabel terikat dalam penelitian ini adalah hasil belajar IPA siswa. Teknik pengumpulan data dalam penelitian ini menggunakan lembar tes (soal) hasil belajar IPA siswa. Adapun jenis lembar tes yang digunakan adalah lembar tes tertutup. Instrumen penelitian yang digunakan oleh peneliti adalah dengan menggunakan lembar tes hasil belajar siswa yang secara langsung datanya dapat diperoleh pada saat kegiatan pembelajaran berlangsung. Instrument penilaian yang akan di uji adalah validitas isi. Validasi isi adalah derajat di mana sebuah tes mengukur cakupan subtansi yang diukur (Darmadi, 2011: 117). Validitas isi ditentukan melalui pertimbangan para ahli untuk menvalidkan instrument yang digunakan, ahli pertma adalah Waridah, M.Pd pakar Matematika dan IPA STKIP Melawi selaku validator satu dan ahli kedua adalah Abdurrahman, S.Pd., SD Guru kelas VI SDN 11 Nanga 
Pinoh selaku validator dua. Persyaratan teknik analisis data menggunakan dua uji, yaitu Uji Normalitas dan Uji Homogenitas. Uji Normalitas yang digunakan dalam penelitian ini adalah dengan menggunakan uji liliefors. Sedangkan Uji Homogenitas adalah pengujian mengenai sama tidaknya variansi- variansi dua buah distribusi atau lebih. Uji analisis data tersebut adalah menggunakan Uji t dan Uji N-Gain.

\section{HASIL DAN PEMBAHASAN}

Budiningsih (2004:58) mengatakan bahwa belajar menurut pandangan kontruktivistik merupakan suatu proses pembentukan pengetahuan. Pembentukan ini harus dilakukan oleh si belajar. ia harus aktif melakukan kegiatan, aktif berpikir, menyusun konsep dan memberi makna tentang hal-hal yang sedang dipelajari. Guru memang dapat dan harus mengambil prakarsa untuk menata lingkungan yang memberi peluang optimal bagi terjadinya belajar. namun yang akhirnya paling menentukan terwujudnya gejala belajar niat belajar siswa sendiri. Hasil belajar dalah perubahan perilaku yang terjadi setelah mengikuti proses belajar mengajar sesuai dengan tujuan pendidikan (Purwanto, 2014: 54). Karena belajar itu sendiri merupakan susatu proses dari seseorang yang berusaha untuk memperoleh suatu bentuk perubahan perilaku relatif menetap. Dalam kegiatan pembelajaran atau kegiatan intruksional, biasanya guru menetapkan tujuan belajar. anak- anak yang berhasil dalam belajar adalah yang berhasil mencapai tujuan-tujuan pembelajaran atau tujuan instruksional. Untuk mengetahui apakah hasil belajar yang dicapai telah sesuai dengan tujuan yang dikehendaki dapat diketahui melalui evaluasi.

Penelitian ini telah dilaksanakan di SDN 11 Nanga Pinoh bahwa hasil belajar siswa dapat meningkat yang dibuktikan dengan hasil perhitungan uji $\mathrm{t}$ data pretest dan posttest, masing-masing nilai rata- rata 60,46 untuk data pretest dan 77, 47 untuk data posttest sehingga diperoleh nilai $\mathrm{T}_{\text {hitung }}$ sebesar 3,75 dan $\mathrm{T}_{\text {tabel }}$ sebesar 2,10. Karena $\mathrm{T}_{\text {hitung }}$ lebih besar dari $\mathrm{T}_{\text {tabel }}$ maka dapat disimpulkan berdasarkan hipotesis bahwa "Terdapat pengaruh" maka Ha diterima setelah diterapkan model pembelajaran bamboo dancing. Sedangkan hasil perhitungan uji N-Gain bahwa yang berada dalam kategori rendah sebanyak 7 orang siswa, yang kategori sedang sebanyak 16 orang siswa, dan di kategori tinggi sebanyak 6 orang siswa. Dengan rumus perhitungan uji N-Gain, yaitu:

$$
\mathrm{g}=\frac{S_{\text {Post }}-S_{\text {Pre }}}{S_{\text {Maks }} S_{\text {Pre }}} \text { keterangan: } \mathrm{g}=\text { gain }
$$

$$
\begin{aligned}
& \text { Spost= Skor Posttest } \\
& \text { Spre= Skor Pretest } \\
& \text { Smaks }=\text { Skor Maksimal }
\end{aligned}
$$


Hasil Perhitungan uji N- Gain, contoh di kategori rendah:

$$
g=\frac{60,00-53,33}{100-53,33}=\frac{6,67}{46,67}=0,1 \quad \text { (Kategori }
$$

Rendah)

$$
\mathrm{g}=\frac{60,00-4,00}{100-40,00}=\frac{20,00}{60,00}=0,3
$$

(Kategori Sedang)

$$
\mathrm{g}=\frac{100,00-80,00}{100-80.00}=\frac{20,00}{20,00}=1,0
$$

(Kategori Tinggi)

Disimpulkan bahwa terdapat pengaruh secara signifikan hasil belajar mata pelajaran IPA akibat penggunaan model pembelajaran bamboo dancing dan terjadi perbedaan hasil belajar sebelum dan sesudah penggunaan model pembelajaran bamboo dancing di kelas VI SDN 11 Nanga Pinoh.

Hasil penelitian yang diterapkan dengan menggunakan model pembelajaran bamboo dancing pada proses pembelajaran melibatkan bagaimana siswa lebih aktif serta melatih pengetahuan dan keterampilan yang mereka miliki dalam mengikuti pembelajaran Ilmu Pengetahuan Alam (IPA) siswa lebih aktif dan memahami dalam mengikuti belajar kelompok, siswa dengan menunjukkan kerjasama yang baik dalam kelompok melalui dengan membantu teman yang berkemampuan lemah. Oleh karena itu model pembelajaran bamboo dancing dapat menciptakan suasana belajar yang menyenangkan.

\section{SIMPULAN}

Menggunakan model pembelajaran bamboo dancing diperoleh nilai pretest rata - rata 60,46 dengan nilai terendah 0,00 dan nilai tertinggi 86,66 , sedangkan dari nilai posttest diperoleh nilai rata-rata 77,47 dengan nilai terendah 46,66 dan nilai tertinggi 100,00 setelah diberi perlakuan. Hasil perhitungan uji-t diperoleh $\mathrm{T}_{\text {hitung }}$ sebesar 3,75 dan $\mathrm{T}_{\text {tabel }}$ sebesar 2,10, karena $\mathrm{T}_{\text {hitung }} 3,75 \geq \mathrm{T}_{\text {tabel }} 2,10$. Sedangkan hasil perhitungan uji N-Gain diperoleh kategori rendah sebanyak 7 orang siswa, yang kategori sedang sebanyak 16 orang siswa, dan di kategori tinggi sebanyak 6 orang siswa. Maka Ho ditolak dan Ha diterima. Jadi $\mathrm{Ha}=$ terdapat pengaruh secara signifikan hasil belajar mata pelajaran IPA akibat penggunaan model pembelajaran bamboo dancing dan terjadi perbedaan hasil belajar sebelum dan sesudah penggunaan model pembelajaran bamboo dancing di kelas VI SDN 11 Nanga Pinoh.

\section{DAFTAR PUSTAKA}

Budiningsih, C. A. 2004. Belajar dan Pembelajaran. Jakarta: Rineka Cipta.

Satori, D. 2013. Metodologi Penelitian Kualitatif. Bandung: Alfabeta.

Huda, M. 2013. Model-model Pengajaran dan Pembelajaran. Yogyakarta: Pustaka Pelajar. 
Jurnal Pendidikan Dasar, 6 (1) Juni 2018

Masrurah. 2010. Tahap-Tahap

Perkembangan Kognitif. (online)

tersedia:http//valmband.multiply.com/j

ournal/item/12 (tanggal unduh 12

Februari 2012)

Purwanto. 2014. Evaluasi Hasil Belajar.

Yogyakarta: Pustaka Belajar.

Sari, M. 2011. Pengertian Hasil Belajar. tersedia di https//www. Google. $\mathrm{Com} / \mathrm{search}=$ pengertian hasil belajar. Tanggal buka 28 Maret 2014.

Shoimin. A. 2016. 68 Model-model Pembelajaran Inovatif dalam Kurikulum 2013. Yogyakarta: Ar-Russ Media.

Sugiyono. 2015. Metode Penelitian Kualitatif, Kuantitatif dan $R \& D$. Jakarta: Alfabeta 